[American Journal of Science, Vol. 305, June, September, October, 2005, P. 645-660]

\title{
MULTIPLE SULFUR ISOTOPE FRACTIONATIONS IN BIOLOGICAL SYSTEMS: A CASE STUDY WITH SULFATE REDUCERS AND SULFUR DISPROPORTIONATORS
}

\author{
DAVID T. JOHNSTON*† ${ }^{\dagger}$, JAMES FARQUHAR*, BOSWELL A. WING*, \\ ALAN J. KAUFMAN*, DONALD E. CANFIELD**, and KIRSTEN S. HABICHT**
}

\begin{abstract}
Multiple sulfur isotope measurements of sulfur compounds associated with dissimilatory sulfate reduction, elemental sulfur disproportionation and sulfite disproportionation indicate that different types of metabolic processes impart different multiple isotope signatures. An established network for sulfate reduction was used previously to explain the multiple isotope variability. Here, we revisit that treatment and expand it to branching networks representative of biological sulfur disproportionation, in an attempt to understand multiple sulfur isotope fractionations associated with that metabolism. We use this context to interpret experimental data for both sulfate reducers and sulfur compound disproportionators. We explore the types of information about material flow through these metabolic processes that can be extracted by using multiple sulfur isotope data. The different multiple sulfur isotope relationships $\left(\Delta^{33} S^{\prime}\right.$ and $\left.\lambda\right)$ allow various metabolic processes to be distinguished from one another, even when $\delta^{34} \mathrm{~S}$ fractionations are similar, providing a tool that can be used to interpret and identify different types of biological sulfur fractionations in the geologic record.
\end{abstract}

\section{INTRODUCTION}

Dissimilatory sulfate reduction likely played an important role in determining the isotopic composition of sedimentary sulfides and oceanic sulfate preserved in the geologic record. It has been proposed that disproportionation of intermediate sulfur species (that is the metabolic production of both an oxidized and reduced endmember) has also played a role in determining the magnitude of the fractionation within that record (Canfield and Thamdrup, 1994). The relative impact of these two metabolisms on the global sulfur isotopic record remains unknown. Habicht and Canfield (2002) have attempted to constrain the relative contribution of these two metabolisms in a number of modern environments. Pinpointing a robust method to differentiate between these metabolisms will make it possible to test models of ocean chemistry and of microbial evolution. In this study, we examine the multiple sulfur isotope signatures of products from experiments with dissimilatory sulfate reducers and sulfur disproportionators, and then integrate these results with models of material flow through metabolic networks as a first step toward addressing these questions.

Experimental studies of sulfate-reducing bacteria under different physical and chemical conditions have established a likely biochemistry for sulfate reduction (Peck, 1959, 1961; Rees, 1973; Castro and others, 2000; Detmers and others, 2001; Canfield, 2001). Rees (1973) described sulfate reduction using the network,

$$
\mathrm{SO}_{4(\text { out })}^{=} \underset{2}{\stackrel{1}{\rightleftarrows}}\left(\mathrm{SO}_{4(\mathrm{in})}^{=} \underset{5 \mathrm{a}}{\stackrel{4 \mathrm{a}}{\rightleftarrows}} \mathrm{APS} \underset{5 \mathrm{~b}}{\stackrel{4 \mathrm{~b}}{\rightleftarrows}} \mathrm{SO}_{3}^{=}\right) \stackrel{3}{\rightarrow} \mathrm{H}_{2} \mathrm{~S}
$$

where the brackets represent the cell wall, APS is adenosine-5'-phosphosulfate, and the numbers represent reaction pathways capable of fractionating material. The upper net

\footnotetext{
*Department of Geology and ESSIC, University of Maryland, College Park, Maryland 20742

**DCESS and Institute of Biology, Southern Denmark University, Campusvej 55, 5230 Odense M, Denmark

${ }^{\dagger}$ Corresponding author: David Johnston, dtj@geology.umd.edu
} 
fractionation limit for this pathway is roughly 50 permil in $\delta^{34} \mathrm{~S}$ (Harrison and Thode, 1958; Kaplan and Rittenburg, 1964; Kemp and Thode, 1968; Chambers and others, 1976; Canfield, 2001). Since sulfate reducing bacteria impart large sulfur isotopic fractionations, and considering that dissimilatory sulfate reduction accounts for over 50 percent of the organic carbon oxidation in modern marine sediments, this process is considered one of the most important controls on the sulfur isotope record (Jørgensen, 1982; Thamdrup and others, 1996; Canfield, 2001; Habicht and Canfield, 2002).

Our understanding of sulfur disproportionation is less well developed. Disproportionation uses various sulfur intermediates (elemental sulfur, sulfite, and thiosulfate) and produces both oxidized (sulfate) and reduced (hydrogen sulfide) end-members (Bak and Pfenning, 1987; Canfield and Thamdrup, 1994; Thamdrup and others, 1994; Canfield and Teske, 1996; Finster and others, 1997; Habicht and others, 1998; Cypionka and others, 1998). In the case where sulfite is disproportionated, the reaction proceeds as (Frederikson and Finster, 2003),

$$
\mathrm{SO}_{3}^{=} \underset{2}{\stackrel{1}{\rightleftarrows}}\left(\underset{\substack{\mathrm{SO}_{3(\mathrm{in})}^{=} \\ \mathrm{H}_{2} \mathrm{~S}}}{\stackrel{4 \mathrm{a}}{\rightleftarrows}} \underset{5 \mathrm{a}}{\rightleftarrows} \mathrm{APS} \underset{5 \mathrm{~b}}{\stackrel{4 \mathrm{~b}}{\rightleftarrows}} \mathrm{SO}_{4(\text { in })}^{=}\right) \underset{7}{\stackrel{6}{\rightleftarrows}} \mathrm{SO}_{4(\text { out })}^{=}
$$

whereas when elemental sulfur is disproportionated,

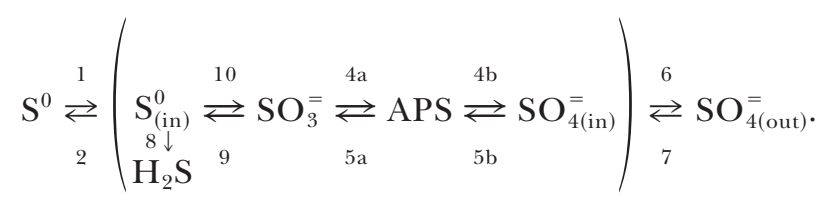

Fractionations in sedimentary sulfides that exceed those produced by sulfate reduction have been attributed to the disproportionation of intermediate sulfur species (Jørgensen 1990a, 1990b; Jørgensen and Bak, 1991; Canfield and Thamdrup, 1996). These intermediates are naturally present in low concentrations (Troelsen and Jørgensen, 1982; Thamdrup and others, 1994) but when they are disproportionated, they can impart large fractionations (up to $70 \%$ in $\delta^{34} \mathrm{~S}$ ) on the sulfur isotope record (Thamdrup and others, 1993; Canfield and Teske, 1996; Habicht and others, 1998; Habicht and Canfield, 2002).

Studies of modern seafloor ecosystems have used both microbial and geochemical techniques to examine the fractionation between product sulfides and residual pore water sulfate (Habicht and Canfield, 2002). This approach provides convincing isotopic evidence for the influence of disproportionation in some modern environments and further supports the argument that disproportionating bacteria played an important role in the geological record of sulfur isotope fractionations. However, it is not possible to apply this method directly to the ancient geological record due to a lack of contemporaneous sulfide and pore water sulfate, and because it is not possible to study cultures of the indigenous sulfate-reducing bacteria in the same way as Habicht and Canfield (2002).

Here we report on a new multiple isotope tool to study the relative influences of dissimilatory sulfate reduction and sulfur disproportionation on the sulfur isotope record. We demonstrate that ${ }^{33} \mathrm{~S}$ can be used in conjunction with ${ }^{34} \mathrm{~S}$ to differentiate the signatures of biological sulfate reduction and biological disproportionation. In the geologic record it is suggested that these variations can be distinguished from those produced by nonbiological processes and hence provide constraints on environmental evolution throughout the Proterozoic Eon. Our approach may allow for the evaluation 
of fractionation processes contributing to the sulfur isotope record in ancient and modern systems.

\section{ISOTOPIC NOTATION}

We use a series of terms to describe our isotope data beginning with the standard delta notation,

$$
\delta^{3 x} S=\left(\frac{\left(\frac{{ }^{3 x} S}{{ }^{32} S}\right)_{\text {sample }}}{\left(\frac{{ }^{3 x} S}{{ }^{32} S}\right)_{\text {reference }}}-1\right) \times 1000,
$$

where ${ }^{3 \mathrm{x}} \mathrm{S}$ is either ${ }^{33} \mathrm{~S}$ or ${ }^{34} \mathrm{~S}$. A logarithmic version of $\delta$, noted as term $\delta^{\prime}$, was chosen to represent the isotopic composition of our samples to remain consistent with other notations (see below). Taken from Hulston and Thode (1965), we define $\delta^{\prime}$ logarithmically as,

$$
\delta^{3 \mathrm{x}} \mathrm{S}^{\prime}=1000 \ln \left(1+\frac{\delta^{3 \mathrm{x}} \mathrm{S}}{1000}\right)
$$

Using $\delta^{3 \mathrm{x}} \mathrm{S}^{\prime}$, we note the difference in composition between two reservoirs (A and B) as $\delta^{3 \mathrm{x}} \mathrm{S}_{\mathrm{B}}^{\prime}-\delta^{3 \mathrm{x}} \mathrm{S}_{\mathrm{A}}^{\prime}$.

We use $\Delta^{33} \mathrm{~S}^{\prime}$ to describe the deviation of a sample datum from a reference fractionation line and define $\Delta^{33} \mathrm{~S}^{\prime}$ as

$$
\Delta^{33} \mathrm{~S}_{\mathrm{A}}^{\prime}=\delta^{33} \mathrm{~S}_{\mathrm{A}}^{\prime}-{ }^{33-34} \lambda_{\mathrm{RFL}} * \delta^{34} \mathrm{~S}_{\mathrm{A}}^{\prime},
$$

where $\lambda_{\text {RFL }}$ defines the relationship between $\delta^{34} S^{\prime}$ and $\delta^{33} S^{\prime}$ for the reference fractionation line (Ono and others, 2003; Young and Galy, 2004). $\Delta^{33} \mathrm{~S}^{\prime}$ differs only slightly from $\Delta^{33} S\left(=\delta^{33} S-1000 *\left[\left(1+\delta^{34} S / 1000\right)^{\lambda}-1\right]\right)$ used in previous studies when isotopic compositions are near zero (Farquhar and others, 2000; Farquhar and Wing, 2003). We use a value of 0.515 for ${ }^{33-34} \lambda_{\mathrm{RFL}}$ to remain consistent with prior studies (for example Hulston and Thode, 1965).

Many fractionation processes depend strongly on the relative mass difference between the isotopes, resulting in highly correlated variations for $\delta^{33} S^{\prime}$ and $\delta^{34} S^{\prime}$ (Hulston and Thode, 1965; Farquhar and others, 2003). These variations are described by

$$
{ }^{33-34} \theta=\left[\frac{\ln \left({ }^{33} \alpha_{\mathrm{B}-\mathrm{A}}\right)}{\ln \left({ }^{34} \alpha_{\mathrm{B}-\mathrm{A}}\right)}\right],
$$

which is a theoretical relationship between fractionation factors $(\alpha)$ and reflects a specific fractionation process. Current convention describes observed variations for $\delta^{33} \mathrm{~S}^{\prime}$ and $\delta^{34} \mathrm{~S}^{\prime}$ using

$$
{ }^{33-34} \lambda=\frac{\delta^{33} S_{\mathrm{B}}^{\prime}-\delta^{33} \mathrm{~S}_{\mathrm{A}}^{\prime}}{\delta^{34} \mathrm{~S}_{\mathrm{B}}^{\prime}-\delta^{34} \mathrm{~S}_{\mathrm{A}}^{\prime}},
$$

where A and B represent different sulfur reservoirs (Miller, 2002).

In this study there is a distinction between isotopic fractionation processes, which are described using $\alpha$ and $\theta$, and observed isotopic fractionations, which are described using $\delta^{3 \mathrm{x}} \mathrm{S}^{\prime}$ and $\lambda$ (Mook, 2000; Farquhar and others, 2003; Angert and others, 2003). We use $\alpha$ and $\theta$ as input values in our modeling. $\theta$ is largely a theoretical term because it 
is difficult to determine experimentally. In this study, we use $\lambda$ to describe both the fractionations we observe in our experiments and the fractionations predicted from our modeling. $\delta^{3 \mathrm{x}} \mathrm{S}^{\prime}$ and $\lambda$ are "net" quantities that can include the effects of many processes and mass-balance (Hayes, 2001; Farquhar and others, 2003). Logarithmic definitions of $\delta^{3 \mathrm{x}} \mathrm{S}^{\prime}$ and $\Delta^{33} \mathrm{~S}^{\prime}$ are used because they provide a straightforward way to relate $\lambda$ to isotopic compositions.

\section{MASS-DEPENDENCE}

Theoretical work by Urey (1947) and Bigeleisen and Mayer (1947) provides the foundation for our understanding of equilibrium mass-dependent isotopic fractionations. The predictions made using their formulae, and those of subsequent studies that describe other physical and chemical mass-dependent isotopic fractionations, have been applied to multiple isotope systems to learn more about the processes that operate in nature (Farquhar and others, 2003). Advancements in analytical precision allow for systems such as the four stable isotopes of sulfur to be more thoroughly studied experimentally.

Isotopic fractionation processes have been traditionally grouped into several overarching categories that include both equilibrium and kinetic processes. Equilibrium fractionations described by Urey (1947) and Bigeleisen and Mayer (1947) reflect the minimization of free energy associated with isotopic exchange reactions. Kinetic fractionations comprise a much larger group of processes that are characterized by unidirectional reactions and transport. Transition state theory has been applied to kinetic fractionations by Bigeleisen and Wolfsberg (1958), who describe chemical kinetic isotopic fractionations in terms of the vibrational energies of the transition state, those of the reactants, and also the reaction path and its relationship to the potential energy surface that describes the different states. Other authors describe kinetic fractionations in terms of the relationship between velocity and kinetic energy for isotopically substituted species (Matsuhisa and others, 1978; Craig and others, 1988; Mook, 2000; Young and others, 2002; Schauble, 2004). It is important to recognize that each of these treatments applies in a different physical-chemical situation, and that each of these treatments has different implications for the isotopic fractionations. Further, some studies have referred to metabolic fractionation processes as kinetic fractionations (Kaplan, 1975). We prefer to make a distinction between fractionation effects that are produced by multi-step metabolic and biogeochemical processes and those that are intrinsic to individual chemical and physical processes (for example, Urey, 1947; Bigeleisen and Mayer, 1947; Bigeleisen and Wolfsberg, 1958; Matsuhisa and others, 1978; Craig and others, 1988; Mook, 2000; Young and others, 2002; Schauble, 2004).

The possibility of different mass-dependent fractionations arising from different equilibrium and kinetic fractionation processes is well documented (Bigeleisen and Wolfsberg, 1958; Matsuhisa and others, 1978; Mook, 2000; Young and others, 2002; Schauble, 2004; Young and Galy, 2004). Values of $\theta$ produced by equilibrium isotopic exchange of sulfur between sulfur species have been constrained using the theoretical treatment of Urey (1947) and are generally near 0.515 for ${ }^{33-34} \theta$. Determinations of ${ }^{33-34} \theta$ produced by kinetic processes are more variable, falling between 0.500 and 0.515 and depend on the nature of the fractionation process responsible for the isotopic fractionations.

Values of $\lambda$ produced by multi-step metabolic processes described by Farquhar and others (2003) depend on the structure of the network, the relative amounts of material that are transferred through the metabolic network, and on the isotopic fractionations $(\alpha$ and $\theta$ ) of its constituent steps. Because of the dependence on material transfer and network structure, the values of $\lambda$ can be more variable than the values of $\theta$ for all constituent steps within any given network. All of the modeling efforts 
presented in the text assumes a ${ }^{33-34} \theta=0.5145$, which is an equilibrium value for exchange between sulfate and hydrogen sulfide at $20^{\circ} \mathrm{C}$ (Farquhar and others, 2003). We recognize that our calculations may later be refined with more precise assignments of ${ }^{33-34} \theta$ for each of the constituent network steps, but do not explore this aspect in the present study.

\section{MODELING}

In a recent study, Farquhar and others (2003) examined how the flow of sulfur through simple metabolic networks can affect the isotopic fractionations in systems with three or more stable isotopes of the same element. These authors took a previously published metabolic network that describes sulfate reduction (Rees, 1973) and adapted it to describe the isotopic fractionations involving the four sulfur isotopes. These predictions are represented by a flow-net that is contoured by a pair of relative flux terms, $f_{3}$ and $f_{5} \cdot f_{3}=\varphi_{3} /\left(\varphi_{3}+\varphi_{2}\right)$ and $f_{5}=\varphi_{5} /\left(\varphi_{5}+\varphi_{3}\right)$, where $\varphi_{\mathrm{j}}$ is a term describing the amount of material moving along pathway $j . f_{3}$ indicates the relative amount of material leaving the cell as hydrogen sulfide (pathway 3 in equation 1) as opposed to leaving the cell as sulfate (pathway 2 in equation 1 ), whereas $f_{5}$ represents the relative internal backflow of sulfur (pathways $5 \mathrm{a}$ and $5 \mathrm{~b}$ in equation 1 ). These flow-nets illustrate the dependence of $\lambda$ on the intercellular recycling of sulfur $\left(f_{5}\right)$ and the internal/external exchange of sulfate $\left(f_{3}\right)$.

An important result from this treatment is that values for $\lambda$ will be less than $\theta$ for all values of $f$ other than 0 and 1 if the fractionation factors $(\alpha)$ are less than 1.00. The converse is true when the fractionation factors are greater than 1.00. In more complex networks with multiple fractionation factors, some of which are greater than 1 and some that are less than $1, \lambda$ can be greater than or less than $\theta$ depending on the values of $f$. When values of $f=0$ or $1, \lambda$ equals $\theta$. Another consequence from this treatment is that the solution to progressively more and more complex networks can be obtained by nesting the solutions for simple networks (see also Rees, 1973). In other words, the fractionation factors for multiple steps are multiplicative.

Modeling disproportionation networks can be undertaken by adapting a similar treatment to the disproportionation network structure. Farquhar and others (2003) examined a very simple branching network component without backflow and noted that the mass-dependent factor, $\lambda$, between the products of this network would be a weighted average of the $\theta$ 's for each of the branches. This treatment can be expanded to branching networks with backflow by applying the ideas above. If the fractionation factors along a branch are greater than 1.00, such as is the case along oxidative branches for sulfur disproportionation, the net $\lambda$ values have the potential to be greater than the constituent $\theta$ values for all values of $f$ other than 0 and 1 . For example, to produce $\lambda$ values greater than 0.5145 for a branching network with all $\theta=0.5145$, a back reaction along the oxidative branch of the network (similar to those seen in equations 2 and 3) must be employed. These principles are used below to interpret our experimental results.

\section{METHODS}

Pure cultures of sulfate-reducing bacteria were grown according to media recipes recommended by Deutsche Sammlung von Mikroorganismen, Braunschweig, Germany (DSM strain \# 3382 and 10085 respectively below). Inoculated solutions were prepared under anaerobic conditions with a $\mathrm{N}_{2}$ atmosphere and without the initial addition of sulfate or substrate. Desulfobacterium autotrophicum was grown under a $\mathrm{H}_{2} / \mathrm{CO}_{2}$ atmosphere where atmospheric pressure was monitored, whereas Desulfospira jorgensenii was provided an organic substrate (Na-pyruvate). Cultures were grown in batch and harvested during the late exponential growth phase. Samples were fixed and 
metabolic activity terminated through the addition of a 20 percent Zinc Acetate solution.

Sulfide concentrations $( \pm 5 \% \mathrm{SD})$ are determined photometrically using a methylene blue technique (Cline, 1969), and later distilled in $6 \mathrm{~N} \mathrm{HCl}$, liberating $\mathrm{H}_{2} \mathrm{~S}$, which was then reacted with $\mathrm{AgNO}_{3}$ to produce $\mathrm{Ag}_{2} \mathrm{~S}$. Sulfate and thiosulfate concentrations $( \pm 1 \% \mathrm{SD})$ were determined via ion chromatography after the addition of a bicarbonate buffer. Sulfates were originally precipitated as $\mathrm{BaSO}_{4}$ and then further reduced (Thode and others, 1961; Forrest and Newman, 1977) to CdS, and then finally to $\mathrm{Ag}_{2} \mathrm{~S}$.

Cell growth was monitored through optical density measurements at $670 \mathrm{~nm}$. Optical density was calibrated to cell numbers by staining cells with DAPI and counting them under UV light. As published by Detmers and others (2001), cell specific reduction rates (csSRR) during exponential phase growth are represented by,

$$
\operatorname{csSRR}=\frac{\mathrm{SO}_{4(2)}^{2-}-\mathrm{SO}_{4(1)}^{2-}}{\frac{\left(\mathrm{cn}_{(1)}+\mathrm{cn}_{(2)}\right)}{2} \times\left(\mathrm{T}_{(2)}-\mathrm{T}_{(1)}\right)} .
$$

where subscripts 1 and 2 represent different sampling times. Here, ' $\mathrm{SO}_{4(2)}^{2-}$ ' is the sulfate concentration at time (2), ' $\mathrm{cn}$ ' is cell number and ' $\mathrm{T}$ ' is time.

The samples used for the disproportionation experiments were generated in the studies of Canfield and others (1998) for elemental sulfur disproportionation and Habicht and others (1998) for sulfite disproportionation. Product ratios $\left(\mathrm{SO}_{4}: \mathrm{H}_{2} \mathrm{~S}\right)$ included in these publications serve as mass-balance parameters when interpreting isotope results.

For isotopic analyses, $\mathrm{Ag}_{2} \mathrm{~S}$ was reacted with excess $\mathrm{F}_{2}$ at $200{ }^{\circ} \mathrm{C}$ in Ni-reaction vessel to produce $\mathrm{SF}_{6} \cdot \mathrm{SF}_{6}$ was purified using cryogenic and gas chromatographic techniques. The isotopic composition of $\mathrm{SF}_{6}$ was determined using a dual inlet, ThermoFinnigan MAT 253 gas source mass spectrometer in the University of Maryland stable isotope laboratory.

Twenty-three fluorinations of an internal reference material yielded $\delta^{33} \mathrm{~S}$ of $0.32 \pm$ 0.16 permil, $\delta^{34} \mathrm{~S}$ of $0.62 \pm 0.34$ permil, and $\Delta^{33} \mathrm{~S}$ of $0.008 \pm 0.014$ permil $(2 \sigma)$ relative to the UMd house $\mathrm{SF}_{6}$. Uncertainties for $\Delta^{33} \mathrm{~S}$ are smaller than those for $\delta^{33} \mathrm{~S}$ because variability inherent in the measurement technique leads to correlated clusters of $\delta^{34} \mathrm{~S}$ with $\delta^{33} \mathrm{~S}$ that covary by $\sim 0.5$. Uncertainties on single fluorinations of unknown silver sulfides are estimated to be comparable to those for our internal standard. This estimate of uncertainty does not include uncertainties that may arise from sampling procedures or wet chemical procedures associated with the collection and production of the silver sulfide for the analyses. For the purposes of estimating the uncertainties on $\lambda$, we use the methods of Williams (1967) and assume uncorrelated uncertainties similar to those on individual fluorinations $\left(0.34 \%\right.$ and $0.014 \%$ for $\delta^{34} \mathrm{~S}$ and $\left.\Delta^{33} \mathrm{~S}, 2 \sigma\right)$.

Our modeling technique is presented in Farquhar and others (2003), and outlined earlier in this submission. The model network used for dissimilatory sulfate reduction is presented in Rees (1973) and can be seen in equation (1). In the case of dissimilatory sulfate reduction, we solved for the relationship between the initial sulfate and product hydrogen sulfide. For sulfur disproportionation, we use the networks presented in equations (2) and (3) and a stoichiometry of $4 \mathrm{SO}_{3}^{2-}+2 \mathrm{H}^{+} \rightarrow$ $\mathrm{H}_{2} \mathrm{~S}+3 \mathrm{SO}_{4}^{2-}$ for sulfite disproportionation and $4 \mathrm{~S}^{\mathrm{o}}+4 \mathrm{H}_{2} \mathrm{O} \rightarrow 3 \mathrm{H}_{2} \mathrm{~S}+\mathrm{SO}_{4}^{2-}+2 \mathrm{H}^{+}$ for elemental sulfur disproportionation to solve for both end-members (sulfate and sulfide) as well as the composition of the reactant pool (either elemental sulfur or sulfite) (Thamdrup and others, 1993; Finster and others, 1998; Canfield, 2001). All reactions are modeled with ${ }^{33-34} \theta$ values at 0.5145 . The individual fractionation factors 
for the sulfate reduction pathway are taken as $\alpha=1.003$ for diffusion of sulfate into the cell, and $\alpha=0.975$ for both the internal conversion of sulfate to sulfite and the enzymatic reduction of sulfite to hydrogen sulfide (Rees, 1973). Fractionation factors for the disproportionation networks were taken partly from the sulfate reduction literature (Rees, 1973), with the remaining $\alpha$ values being provided by theoretical calculations presented in table 1 of Farquhar and others (2003).

\section{RESULTS}

Cell specific reduction rates (measured in $f \mathrm{~mol} / \mathrm{cell} /$ day) for both sulfate reduction experiments match well with those published in Detmers and others (2001) for exponential phase growth. Bacterial populations during the experiments reached cell densities of the same magnitude as seen previously with these strains. Concentrations of the sulfate and sulfide pools were monitored and covary (fig. 1). Isotopic compositions for three of the stable isotopes of sulfur as well as the cell-specific metabolic rates and concentration data from sulfate reduction experiments are listed in table 1 . The isotopic composition of the reactant sulfate and the product sulfide for sulfate reduction experiments is reported (table 1), along with the products (sulfide and sulfate) from sulfur disproportionation experiments (table 2). We further report calculated $\Delta^{33} \mathrm{~S}^{\prime}$ and $\lambda$ values for each sample. The isotopic compositions of the sulfate reduction experiments were normalized to the starting sulfate composition and, when possible, sulfur disproportionation experiments were normalized to the composition of the starting sulfur compound. In the case of the Golfo Dulce samples, where no initial sample was available, values were normalized to house $\mathrm{UMd} \mathrm{SF}_{6}$.

\section{Sulfate Reducing Bacteria}

For D. jorgensenii, the product sulfide was depleted in $\delta^{34} \mathrm{~S}^{\prime}$ and the residual sulfate was enriched with respect to the $\delta^{34} S^{\prime}$ values for the starting sulfate (table 1 ). For longer duration experiments, $\delta^{34} \mathrm{~S}^{\prime}$ values of both sulfide and sulfate are more positive. $\Delta^{33} \mathrm{~S}^{\prime}$ values record slight changes in both sulfate and sulfide compositions, with the sulfide becoming more positive and the sulfate becoming more negative. The $\lambda$ values for this experiment ranged from 0.5106 to 0.5114 . Mixing lines between product sulfide and the residual sulfate intersected the initial sulfate composition, therefore satisfying mass balance.

Results for experiments run with $D$. autotrophicum illustrate a sulfide reservoir with depleted $\delta^{34} S^{\prime}$ values and with an enriched $\delta^{34} S^{\prime}$ composition in the sulfate reservoir (table 1 ). As the reaction proceeds, the sulfide composition grows more depleted and the sulfate composition becomes more enriched in $\delta^{34} \mathrm{~S}^{\prime}$. The $\Delta^{33} \mathrm{~S}^{\prime}$ values record slight changes in both sulfide and sulfate composition, with both species migrating towards more positive values. $\lambda$ values for this experiment evolved from 0.5103 to 0.5125 . Mixing lines between the residual sulfate and product hydrogen sulfide intersect the starting composition of the initial sulfate and the data are therefore consistent with isotopic mass balance.

\section{Sulfur Disproportionating Bacteria}

Two experiments with freshwater sulfite disproportionator $D$. thiozymogenes yielded fractionations of up to 31 permil for $\delta^{34} \mathrm{~S}_{\mathrm{H}_{2} \mathrm{~S}}^{\prime} \delta^{34} \mathrm{~S}_{\mathrm{SO}_{4}}^{\prime}$ (table 2). The sulfide pool showed strong $\delta^{34} \mathrm{~S}^{\prime}$ depletions of 23 permil, whereas the sulfate pool was only enriched by 7 permil. The $\Delta^{33} \mathrm{~S}^{\prime}$ values of the two reservoirs is more positive than the starting sulfite by up to 0.15 permil and the average $\lambda_{\mathrm{SO}_{4}-\mathrm{H}_{2} \mathrm{~S}}$ was 0.5164 .

Two sulfite disproportionating experiments with $D$. sulfodismutans produced large

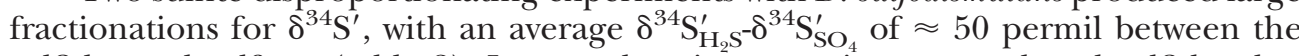
sulfides and sulfates (table 2). Longer duration experiments produced sulfides that were less depleted in $\delta^{34} \mathrm{~S}^{\prime}$ whereas the sulfates became less enriched in $\delta^{34} \mathrm{~S}^{\prime}$. The 


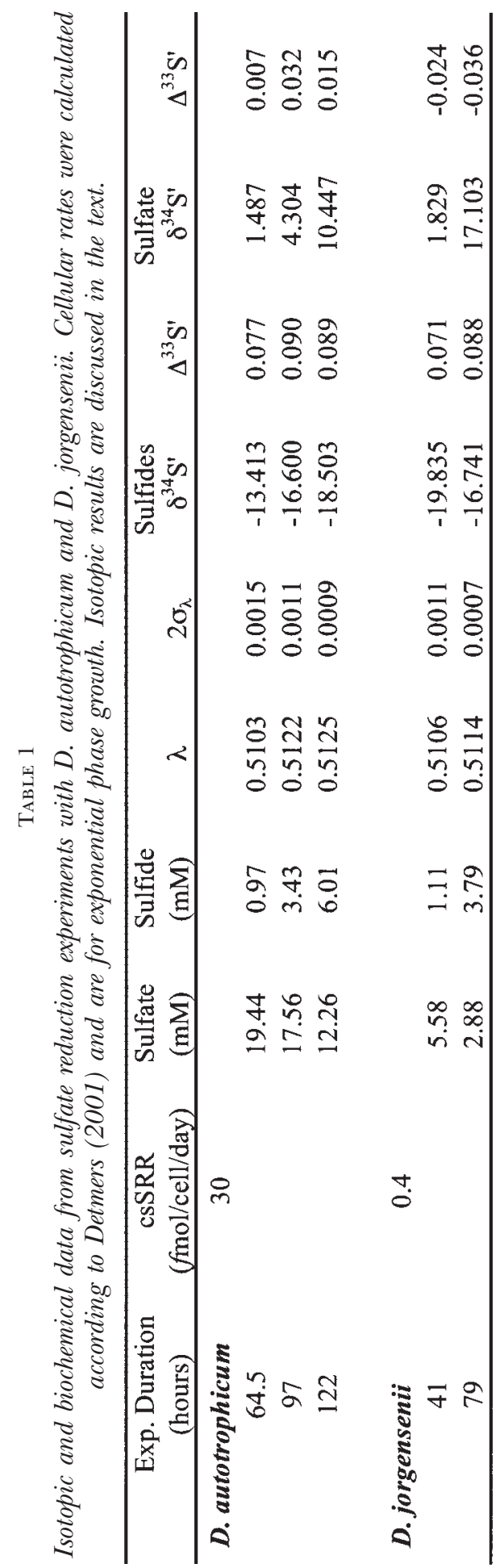




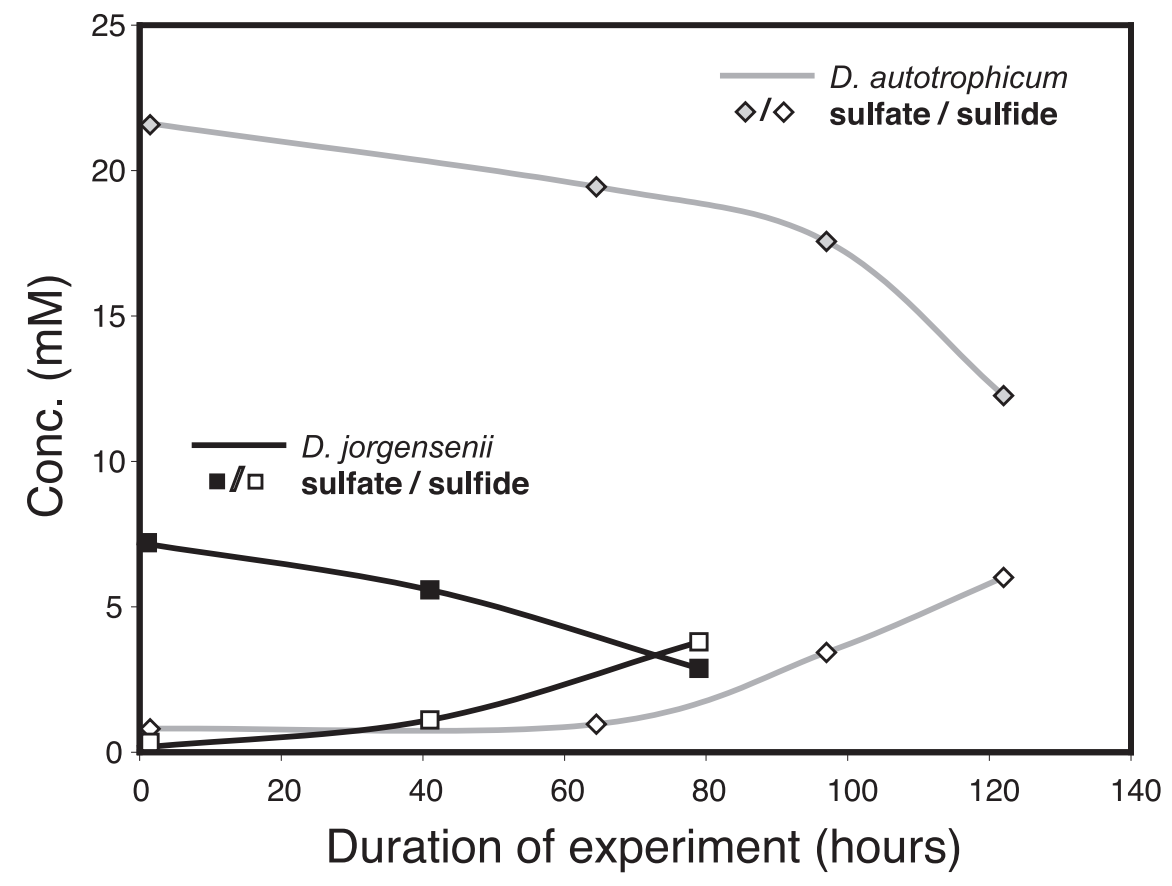

Fig. 1. Concentrations of sulfates and sulfides for sulfate reduction experiments with $D$. autotrophicum and $D$. jorgensenii are plotted against the duration of the experiment. Each symbol represents a time when the experiment was sampled. We note the stoichiometric depletion of sulfate and accumulation of sulfide. Experiments were run until $\sim 50 \%$ of the initial sulfate was consumed. Due to a low csSRR, D. jorgensenii was started at a lower sulfate concentration. This concentration is still large enough not to effect the fractionation produced by the organisms (Habicht and others, 2002).

TABLE 2

Isotopic results obtained for sulfur and sulfite disproportionation experiments. Data for every experiment, except those with the Golfo Dulce culture, which is normalized to UMd house

$S F_{6}$, are referenced to the isotopic composition of the starting materials. Time intervals $A$ and $B$ for the Golfo Dulce samples represent different experiment durations with A preceding $B$.

\begin{tabular}{ccccccc}
\hline $\begin{array}{c}\text { Exp. Duration } \\
\text { (hours) }\end{array}$ & $\lambda$ & $2 \sigma_{\lambda}$ & $\begin{array}{c}\text { Sulfides } \\
\delta^{34} \mathrm{~S}^{\prime}\end{array}$ & $\Delta^{33} \mathrm{~S}^{\prime}$ & $\begin{array}{c}\text { Sulfate } \\
\delta^{34} \mathrm{~S}^{\prime}\end{array}$ & $\Delta^{33} \mathrm{~S}^{\prime}$ \\
\hline D. thiozymogenes & & & & & & \\
99.25 & 0.5166 & 0.0007 & -23.471 & 0.101 & 7.403 & 0.150 \\
99.25 & 0.5161 & 0.0008 & -22.131 & 0.105 & 7.727 & 0.138 \\
D. sulfodismutans & & & & & & \\
114.95 & 0.5145 & 0.0004 & -45.238 & 0.158 & 9.967 & 0.131 \\
114.95 & 0.5148 & 0.0005 & -37.504 & 0.107 & 7.815 & 0.097 \\
Golfo Dulce & & & & & & \\
$\mathrm{B}$ & 0.5187 & 0.0007 & 4.414 & -0.003 & 29.279 & 0.090 \\
\hline & 0.5171 & 0.0008 & 4.208 & 0.003 & 33.482 & 0.064 \\
\hline
\end{tabular}


$\Delta^{33} \mathrm{~S}^{\prime}$ values in both pools recorded significant enrichments of up to 0.16 permil, relative to the starting sulfite. The average observed $\lambda_{\mathrm{H}_{2} \mathrm{~S}-\mathrm{SO}_{4}}$ for this experiment was 0.5147 .

Two experiments with an elemental sulfur disproportionator from Golfo Dulce,

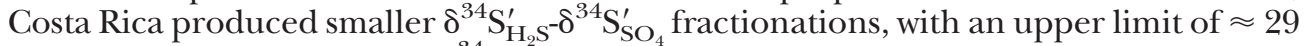
permil (table 2 ). We observe $\delta^{34} \mathrm{~S}^{\prime}$ sulfide values of $\approx 4$ permil, with the complimentary sulfate pool recording a $\delta^{34} \mathrm{~S}^{\prime}$ enrichments of $\approx 30$ permil. The $\Delta^{33} \mathrm{~S}^{\prime}$ values were enriched by up to 0.09 permil in the sulfates, and with $\lambda_{\mathrm{SO}_{4}-\mathrm{H}_{2} \mathrm{~S}}$ of up to 0.5187 .

$\delta^{34} \mathrm{~S}^{\prime}$ measurements highlight the large fractionations between products sulfide and sulfate that are produced by sulfur disproportionation (Thamdrup and others, 1993; Canfield and Teske, 1996; Habicht and others, 1998). The addition of minor isotope data also indicates variations in $\Delta^{33} \mathrm{~S}^{\prime}$, most notably between initial compositions and the products. When coupled, very large fractionations in $\delta^{34} \mathrm{~S}^{\prime}$ and measurable $\Delta^{33} S^{\prime}$ allow for more precise determinations of $\lambda$, and hence greater resolution from $\lambda_{\mathrm{RFL}}$ than for the sulfate reduction experiments.

\section{DISCUSSION}

\section{Interpretation of Experimental Data Using Flow Networks}

Experiments with sulfate reducing bacteria.-The sulfur isotopic fractionations between product hydrogen sulfide and source sulfate in a biological network depend on the structure of the network, the transfer of sulfur within the network, and the isotopic fractionations associated with the transfer pathways. Using the published network for dissimilatory sulfate reduction of Rees (1973), Farquhar and others (2003) demonstrated that it is possible to account for variability in both $\lambda$ and the $\delta^{34} \mathrm{~S}_{\mathrm{H}_{3}}^{\prime} \mathrm{s}^{-\delta^{34}} \mathrm{~S}_{\mathrm{SO}_{4}}^{\prime}$ produced during the reduction of sulfate by A. fulgidus. In this study, we additionally present the multiple sulfur isotope data from experiments with two other sulfate reducers, $D$. autotrophicum and D. jorgensenii (fig. 2). The ranges of isotopic variations produced by these organisms yielded $\lambda$ values that range from 0.5103 to 0.5125 . These $\lambda$ values are significantly less than those predicted for equilibrium exchange between hydrogen sulfide and sulfate between 0 and $120{ }^{\circ} \mathrm{C}(0.5146-0.5150)$, but similar to those predicted for dissimilatory sulfate reduction (0.512) (Farquhar and others, 2003). The relationship between $\lambda$ and the $\delta^{34} \mathrm{~S}_{\mathrm{H}_{2}}^{\prime} \mathrm{S}^{-} \delta^{34} \mathrm{~S}_{\mathrm{SO}_{4}}^{\prime}$ reflects changes in the flow parameters of the sulfate reduction network (eq 1). As described previously (Farquhar and others, 2003), the isotopic composition of experiments with A. fulgidus (culture grown as a continuous culture within a bioreactor) evolved along a contour that defines constant proportions of sulfur diffusion into and out of the cell $\left(f_{3} \approx 0.4\right)$ and variable proportions of internal back reactions between sulfite, APS, and sulfate $\left(f_{5}\right.$ varies from 0.2 to 1.0 ) (see fig. 2).

Experiments with $D$. jorgensenii grown in batch culture produced $\delta^{34} \mathrm{~S}^{\prime}$ fractionations typical of other sulfate reducing bacteria. This experiment evolved in a similar way to A. fulgidus along $f_{3}$ (approximately 0.4 ), but produced fractionations that required $f_{5}$ values from 0.6 to greater than 1.0 (fig. 2). Since it is not possible for $f_{5}$ to exceed 1, these experiments suggest that at least one of the input fractionation factors associated with the internal network steps is slightly incorrect. For instance, it is possible to account for the data using the Rees (1973) network by increasing the fractionation factor for the internal back reaction $\left(\mathrm{SO}_{3}^{=}\right.$to $\mathrm{SO}_{4}^{=}$(in) $)$to 35 permil in $\delta^{34} \mathrm{~S}^{\prime}$ (originally at $25 \%$ ). One possible explanation for the evolution along the $f_{3}$ contour is that this organism is known to metabolize very slowly, as seen by the low specific rates calculated earlier. This may indicate a less dynamic sulfate exchange mechanism.

The isotopic relationships produced by $D$. autotrophicum evolve in a different way than A. fulgidus and D. jorgensenii, but the $\delta^{34} \mathrm{~S}^{\prime}$ fractionations are still consistent with 


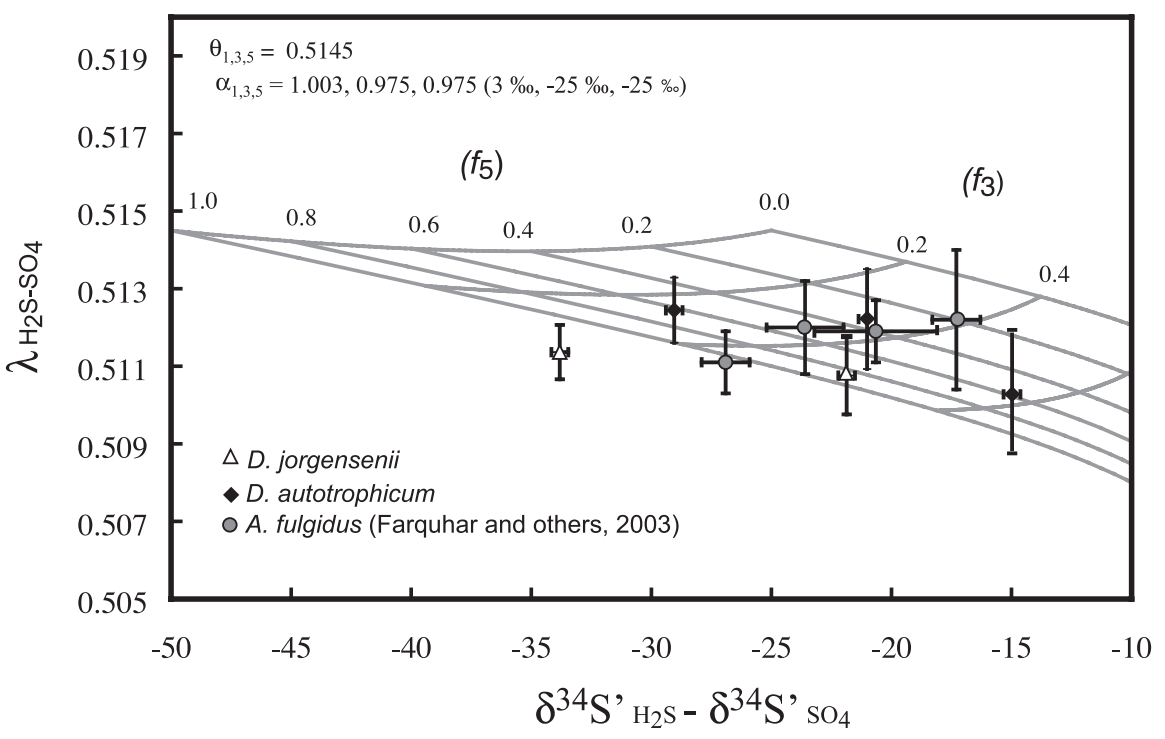

Fig. 2. Plot of $\lambda$ versus $\delta^{34} \mathrm{~S}_{\mathrm{H}_{2} \mathrm{~S}^{-}}^{\prime} \delta^{34} \mathrm{~S}_{\mathrm{SO}_{4}}^{\prime}$ illustrating the effect of the Rees (1973) biosynthetic network (equation 1 in text) on multiple isotopic fractionations between hydrogen sulfide and sulfate. Division of flow is within the network is compactly described by $f_{3}$ which represents the interaction between the enzymatic reduction of sulfite and the sulfate leaving the cell and $f_{5}$ which is the proportion of back reaction from sulfite to sulfate. We include data from Farquhar and others (2003) along with new data from this study. Assumptions in the construction of the model are listed in the figure. The value of 0.5145 was selected on the grounds that it represents a low temperature equilibrium process. Fractionation factors used were taken from Rees (1973). Error bars represent $2 \sigma$ uncertainties. See text and Farquhar and others (2003) for further discussion of the modeling.

sulfate reduction. This experiment follows a contour that defines constant proportions of internal back reactions between sulfite, APS, and sulfate $\left(f_{5} \approx 0.6\right)$ and variable proportions of transport of sulfate into and out of the cell $\left(f_{3}\right.$ varies from 0.3 to 0.6 ) (fig. 2). We interpret variations in $f_{3}$ as a response to the changes in the external sulfate concentration during the batch culture experiments.

The experiments described above represent two fundamentally different types of experiments. In the case of $A$. fulgidus, a bioreactor was used to maintain chemical equilibrium throughout the experiment whereas both $D$. jorgensenii and $D$. autotrophicum were grown in batch mode, where external conditions are constantly evolving and Rayleigh fractionation effects are more likely. However, since all these experiments produced similar $\lambda$ values, we exclude the discussion of Rayleigh distillation effects and conclude that Rayleigh fractionation only has small effects on these systems. Later, more refined studies should revisit this conclusion and test the role of Rayleigh fractionation effects on $\lambda$ in microbial experiments.

This analysis illustrates the potential applications for this approach. Experimental data provides a critical check of the validity of the structure, the fractionation factors, and the flow parameters used in the proposed biological networks. At present, our data do not allow us uniquely to constrain these parameters in the networks, but future work that includes experimental determination of the isotopic compositions of intermediate sulfur pools has the potential to provide this information.

Experiments with elemental sulfur and sulfite disproportionating bacteria.-We use a similar approach to understand the sulfur isotopic fractionations produced by disproportionation networks. In the case of sulfur disproportionation, we interpret the relationship between the products (sulfide and sulfate) rather than between reactant 


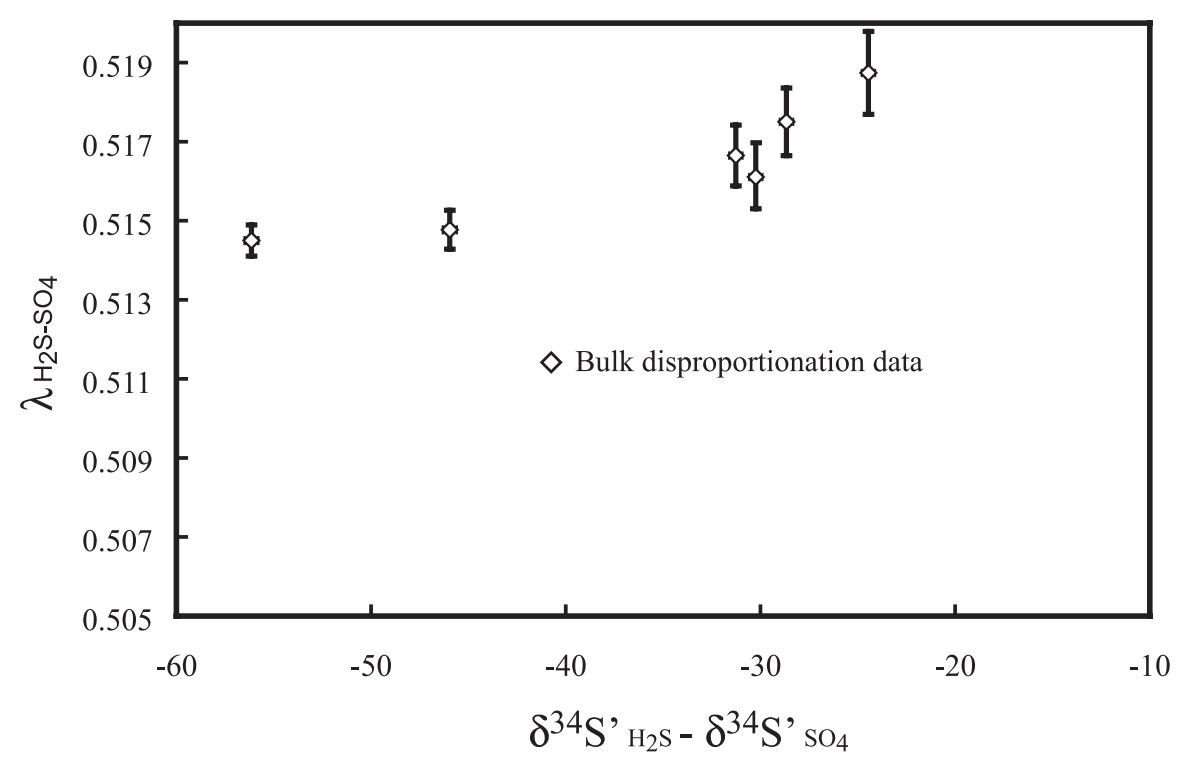

Fig. 3. Plot of $\lambda$ versus $\delta^{34} \mathrm{~S}_{\mathrm{H}_{2} \mathrm{~S}^{-}}^{\prime} \delta^{34} \mathrm{~S}_{\mathrm{SO}_{4}}^{\prime}$ for disproportionation data from experiments with D. thiozymogenes, D. sulfodismutans, and a culture from Golfo Dulce, Costa Rica. Large ${ }^{34} \mathrm{~S}$ fractionations are typical of disproportionation reactions. Error bars represent $2 \sigma$ uncertainties. $\lambda$ values greater than $\lambda_{\text {REF }}$ are interpreted to reflect back flow along the oxidative branch of the disproportionation network (see text for discussion).

and product. The modeling treatment of these disproportionation networks (see eqs 2 and 3) describes the general features that are observed in the experiments, but the calculations can be sensitive to the input parameters, such as $\alpha$ and $\theta$, which remain to be further constrained.

Multiple sulfur isotope measurements from the disproportionation experiments produced $\delta^{34} \mathrm{~S}^{\prime}$ fractionations that range from 23 to 55 permil, consistent with our understanding of disproportionation. The experiments yield $\lambda$ values between product hydrogen sulfide and product sulfate that range from 0.5145 to 0.5187 (fig. 3 ). The sample pairs with the lowest values of $\lambda$ produced the largest $\delta^{34} \mathrm{~S}^{\prime}$ fractionations. The models of Farquhar and others (2003) produce similar values when there is insignificant back reaction (unidirectional flow) after the disproportionation branching point. For sample pairs with more positive $\lambda$ values, the $\delta^{34} \mathrm{~S}^{\prime}$ fractionations are smaller. We interpret these larger $\lambda$ values, in the context of the Farquhar and others (2003) model, as indicating a back reaction in the oxidative branch (pathways 5 and 7 in eq 2 and pathways 5, 7, and 9 in eq 3 ) of the disproportionation network. Although we view $\theta=0.516$ as a natural upper limit for mass-dependent processes, branching networks have been shown to produce inverse fractionation effects, or in our case $\lambda>0.516$, associated with one product of a branching network (Fry, 2003). Back flow along the reductive branch of the disproportionation network conversely reduces the $\lambda$ values in a similar fashion to that of sulfate reduction (see fig. 2). The large range in $\lambda$ values may indicate that internal back flow, primarily along the oxidative branch, is a highly variable characteristic of disproportionation biochemistry. Although the modeling approach provides insight into the first-order fractionation affects, we have been unable to reproduce the data using fractionations similar to those in the sulfate reduction network. The model can be forced to reproduce the data, but requires large $\left(\sim 10 \%\right.$ o in $\left.{ }^{34} \mathrm{~S}\right)$ fractionations associated with sulfite transport into the cell, and very 


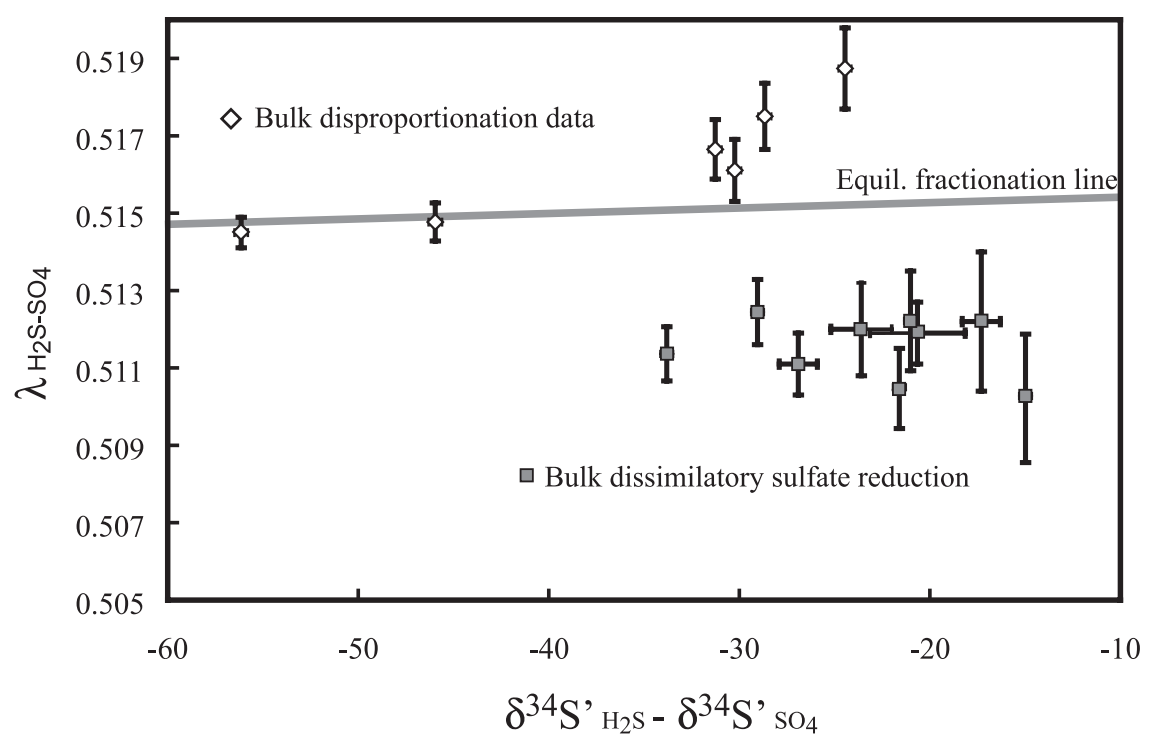

Fig. 4. Plot of $\lambda$ versus $\delta^{34} \mathrm{~S}_{\mathrm{H}_{2} \mathrm{~S}^{-}}^{\prime} \delta^{34} \mathrm{~S}_{\mathrm{SO}_{4}}^{\prime}$ that includes data from all experiments and the A. fulgidus experiment from Farquhar and others (2003). Data from experiments with sulfate reducers plot at values of $\lambda$ that are between 0.5103 and 0.5125 , while data from experiments with sulfite disproportionators and elemental-sulfur disproportionators plot at values of $\lambda$ from 0.5145 to values greater than 0.5187 . Error bars represent $2 \sigma$ uncertainties. The dark gray band is the relationship between $\lambda$ and $\delta^{34} S_{\mathrm{H}_{2} \mathrm{~S}^{-}}^{\prime} \delta^{34} \mathrm{~S}_{\mathrm{SO}_{4}}^{\prime}$ for equilibrium exchange between $\mathrm{H}_{2} \mathrm{~S}$ and $\mathrm{SO}_{4}$ (Farquhar and Wing, 2003). Figures 2 and 3 illustrate two fundamental points. First, most metabolic fractionation processes cannot be approximated by equilibrium isotope exchange. Further, isotope fractionations by sulfur disproportionators are often resolvable from fractionations by sulfate reducers only by considering ${ }^{33} \mathrm{~S}$ in addition to ${ }^{34} \mathrm{~S}$.

large $\left(40-50 \%\right.$ in $\left.{ }^{34} \mathrm{~S}\right)$ fractionations associated with the sulfite-APS-sulfate steps. We feel that the modeling methodologies are resilient, and the focus of future work rests on determining the appropriate network for these metabolisms.

The issue of Rayleigh fractionation influencing $\lambda$ must also be considered in disproportionation experiments. Rayleigh fractionation was an important factor in sulfite disproportionation experiments (Habicht and others, 1998), whereas in elemental sulfur experiments it was not (Canfield and others, 1998). However, since the minor isotope data are similar for both styles of experiment, the fractionations observed are felt to be intrinsic to the process of disproportionation, and not a result of Rayleigh distillation.

\section{Geological and Biological Applications}

Our experiments and their evaluation in the context of metabolic networks demonstrate that it is possible to distinguish between signatures produced by dissimilatory sulfate reducers and sulfur disproportionators, even when the magnitude of the isotopic fractionation is similar. Figure 4 illustrates the relationship between $\lambda$ values and $\delta^{34} S^{\prime}$ fractionations for hydrogen sulfide-sulfate pairs for experiments involving dissimilatory sulfate reducers as well as sulfite and elemental sulfur disproportionators. A line that represents calculated effects of equilibrium fractionations between $\mathrm{H}_{2} \mathrm{~S}$ and $\mathrm{SO}_{4}$ from Farquhar and Wing (2003) is presented on figure 4 as well. Biological disproportionation processes produce $\lambda$ values that converge on equilibrium values for hydrogen sulfide-sulfate exchange $(0.5147)$ when $\delta^{34} \mathrm{~S}^{\prime}$ fractionations are large, but trends to values of $\lambda$ that are greater than 0.5150 when $\delta^{34} \mathrm{~S}^{\prime}$ fractionations are less than approximately 35 permil. Fractionations between $\mathrm{H}_{2} \mathrm{~S}$ and $\mathrm{SO}_{4}$ that are produced by 
dissimilatory sulfate reduction yield $\lambda$ values between 0.5125 and 0.5103 , significantly lower than $\lambda$ values produced by either equilibrium exchange $(0.5147-0.5150)$ or biological disproportionation (0.5147) at the same magnitude $\delta^{34} S^{\prime}$ fractionation.

Under certain conditions, some sulfur disproportionating bacteria can operate as facultative sulfate reducers. In this scenario, we expect that the $\lambda$ associated with reduction be similar to that of the obligate sulfate reducers. Primary disproportionators will only reduce sulfate as a means of survival under conditions where disproportionation is less favorable. In interpreting the geologic record, a sulfur disproportionating bacteria reducing sulfate should be just as diagnostic of the environmental conditions as a sulfate reducing bacteria reducing sulfate.

The ability to distinguish isotopic fractionations produced by dissimilatory metabolisms from those produced by disproportionation metabolisms has potential application for testing hypotheses about the changing role of sulfur metabolisms in the terrestrial sulfur cycle over the course of Earth's history. For instance, Shen and others (2001) have argued that large $\delta^{34} S^{\prime}$ fractionations between pyrite and host barite in 3.45 Ga samples of the Pilbara Group of northwestern Australia reflect dissimilatory sulfate reduction by early bacteria. Moreover, it has been suggested that after $2.5 \mathrm{Ga}$, the record of sulfur isotopes on a global scale cycle bears the signature of sulfate reducing bacteria and that the imprint of disproportionation did not become significant until after approximately $1 \mathrm{Ga}$ (Canfield, 1998, 2001). It has also been suggested that the large positive excursions for $\delta^{34} \mathrm{~S}$ following Neoproterozoic glaciations were caused by distillation of sulfur by sulfate reducing bacteria (Hurtgen and others, 2002). Our findings suggest that determination of the multiple isotope fractionations for these and related samples may provide a new test of these hypotheses as well as potential tests for evidence of metabolic activity and sulfur fractionations in samples relevant to astrobiological studies.

\section{ACKNOWLEDGMENTS}

We acknowledge comments on early versions of this manuscript by L. Tuit. This research was supported by grants from the NSF (EAR0348382), NASA (EXB and NAI), SOAS (International School of Aquatic Sciences) and the Danish National Science Foundation. We also thank P. Søholt and L. Salling for technical support. We appreciate the insightful reviews of Y. Shen and two anonymous reviewers.

\section{REFERENCES}

Angert, A., Rachmilevitch, S., Barkan, E., and Luz, B., 2003, Effects of photorespiration, the cytochrome pathway, and the alternative pathway on the triple isotopic composition of atmospheric $\mathrm{O}_{2}$ : Global Biogeochemical Cycles, v. 17, Article Number 1030.

Bak, F., and Pfennig, N., 1987, Chemolithotrophic growth of Desulfovibrio-Sulfodismutans sp-nov by disproportionation of inorganic sulfur-compounds: Archives of Microbiology, v. 147, p. 184-189.

Bigeleisen, J., and Mayer, M. G., 1947, Calculation of Equilibrium Constants for Isotopic Exchange Reactions: Journal of Chemical Physics, v. 15, p. 261-267.

Bigeleisen, J., and Wolfsberg, M., 1958, Theoretical and experimental aspects of isotope effects in chemical kinetics: Advances in Chemical Physics, v. 1, p. 15-76.

Blunier, T., Barnett, B., Bender, M. L., and Hendricks, M. B., 2002, Biological oxygen productivity during the last 60,000 years from triple oxygen isotope measurements: Global Biogeochemical Cycles, v. 16, Article number 1029 .

Canfield, D. E., 1998, A new model for Proterozoic ocean chemistry: Nature (London), v. 396, p. 450-453. - 2001, Biogeochemistry of sulfur isotopes, in Valley, J. W., and Cole, D. R., editors, Stable Isotope Geochemistry: Reviews in Mineralogy and Geochemistry, v. 43, p. 607-636.

Canfield, D. E., and Teske, A., 1996, Late Proterozoic rise in atmospheric oxygen concentration inferred from phylogenetic and sulphur-isotope studies: Nature, v. 382, p. 127-132.

Canfield, D. E., and Thamdrup, B., 1994, The production of ${ }^{34} \mathrm{~S}$ depleted sulfide during bacterial disproportionation of elemental sulfur: Science, v. 266, p. 1973-1975.

1996, Fate of elemental sulfur in an intertidal sediment: FEMS Microbiology Ecology, v. 19, p. 95-103. 
Canfield, D. E., Thamdrup, B., and Fleischer, S., 1998, Isotope fractionation and sulfur metabolism by pure and enrichment cultures of elemental sulfur-disproportionating bacteria: Limnology and Oceanography, v. 43, p. 253-264.

Castro, H. F., Williams, N. H., and Ogram, A., 2000, Phylogeny of sulfate-reducing bacteria: FEMS Microbiology Ecology, v. 31, p. 1-9.

Chambers, L. A., Trudinger, P. A., Smith, J. W., and Burns, M. S., 1976, Possible boundary-condition in bacterial sulfur isotope fractionation: Geochimica et Cosmochimica Acta, v. 40, p. 1191-1194.

Cline, J. D., 1969, Spectrophotometric determination of hydrogen sulfide in natural waters: Limnology and Oceanography, v. 14, p. 454-458.

Craig, H., Horibe, Y., and Sowers T., 1988, Gravitational Separation Of Gases And Isotopes In Polar Ice Caps: Science, v. 242, p. 1675-1678.

Cypionka, H., Smock, A. M., and Bottcher, M. E., 1998, A combined pathway of sulfur compound disproportionation in Desulfovivrio desulfuricans: FEMS Microbiology Letters, v. 166, p. 181-186.

Detmers, J., Bruchert, V., Habicht, K. S., and Kuever, J., 2001, Diversity of sulfur isotope fractionations by sulfate-reducing prokaryotes: Applied and Environmental Microbiology, v. 67, p. 888-894.

Farquhar, J., and Wing, B. A., 2003, Multiple sulfur isotopes and the evolution of the atmosphere: Earth and Planetary Science Letters, v. 213, p. 1-13.

Farquhar, J., Bao, H. M., and Thiemens, M., 2000, Atmospheric influence of Earth's earliest sulfur cycle: Science, v. 289 , p. $756-758$

Farquhar, J., Johnston, D. T., Wing, B. A., Habicht, K. S., Canfield, D. E., Airieau, S. A., and Thiemens, M. H., 2003, Multiple sulfur isotopic interpretations of biosynthetic pathways: Implications for biological signatures in the sulfur isotope record: Geobiology, v. 1, p. 15-27.

Finster, K., Liesack, W., and Tindall, B. J., 1997, Desulfospira joergensenii, gen. nov, sp. nov, a new sulfate-reducing bacterium isolated from marine surface sediment: Systematic and Applied Microbiology, v. 20, p. 201-208.

Finster, K., Liesack, W., and Thamdrup, B., 1998, Elemental sulfur and thiosulfate disproportionation by Desulfocapsa sulfoexigens sp. nov., a new anaerobic bacterium isolated from marine surface sediment: Applied and Environmental Microbiology, v. 64, p. 119-125.

Forrest, J., and Newman, L., 1977, Ag-110 microgram sulfate analysis for short time resolution of ambient levels of sulfur aerosol: Analytical Chemistry, v. 49, p. 1579-1584.

Frederiksen, T. M., and Finster, K., 2003, Sulfite-oxido-reductase is involved in the oxidation of sulfite in Desulfocapsa sulfoexigens during the disproportionation of thiosulfate and elemental sulfur: Biodegredation, v. 14, p. 189-198.

Fry, B., 2003, Steady state models of stable isotope distributions: Isotopes in Environmental and Health Studies, v. 39, p. 219-232.

Habicht, K. S., and Canfield, D. E., 2002, Isotope fractionation by sulfate-reducing natural populations and the isotopic composition of sulfide in marine sediments: Geology, v. 29, p. 555-558.

Habicht, K. S., Canfield, D. E., and Rethmeier, J., 1998, Sulfur isotope fractionation during bacterial reduction and disproportionation of thiosulfate and sulfite: Geochimica et Cosmochimica Acta, v. 62, p. 2585-2595.

Habicht, K. S., Gade, M., Thamdrup, B., Berg, P., and Canfield, D. E., 2002, Calibration of sulfate levels in the Archean Ocean: Science, v. 298, p. 2372-2374.

Harrison, A. G., and Thode, H. G., 1958, Mechanism of the bacterial reduction of sulphate from isotope fractionation studies: Transactions of the Faraday Society, v. 54, p. 84-92.

Hayes, J. M., 2001, Fractionation of carbon and hydrogen isotopes in biosynthetic processes, in Valley, J. W. and Cole, D. R., editors, Stable Isotope Geochemistry: Reviews in Mineralogy and Geochemistry, v. 43, p. $225-277$.

Hulston, J. R., and Thode, H. G., 1965, Cosmic Ray Produced ${ }^{36} \mathrm{~S}$ and ${ }^{33} \mathrm{~S}$ in Metallic Phase of Iron Meteorites: Journal of Geophysical Research, v. 70, p. 4435-4442.

Hurtgen, M. T., Arthur, M. A., Suits, N. S., and Kaufman, A. J., 2002, The sulfur isotopic composition of Neoproterozoic seawater sulfate: implications for a snowball Earth?: Earth and Planetary Science Letters, v. 203, p. 413-429.

Jørgensen, B. B., 1982, Mineralization of organic-matter in the sea bed - the role of sulfate reduction: Nature, v. 296 , p. $643-645$.

1990a, The sulfur cycle of fresh-water sediments - role of thiosulfate: Limnology and Oceanography, v. 35 , p. $1329-1342$.

1990 b, A thiosulfate shunt in the sulfur cycle of marine-sediments: Science, v. 249, p. 152-154.

Jørgensen, B. B., and Bak, F., 1991, Pathways and microbiology of thiosulfate transformations and sulfate reduction in a marine sediment (Kattegat, Denmark): Applied and Environmental Microbiology, v. 57, p. 847-856.

Kaplan, I. R., 1975, Stable isotopes as a guide to biogeochemical processes: Proceedings of the Royal Society of London, Series B, Biological Sciences, v. 189, p. 183-211.

Kaplan, I. R., and Rittenberg, S. C., 1964, Microbiological fractionation of sulphur isotopes: Journal of General Microbiology, v. 34, p. 195-212.

Kemp, A. L. W., and Thode, H. G., 1968, Mechanism of bacterial reduction of sulphate and of sulphite from isotope fractionation studies: Geochimica et Cosmochimica Acta, v. 32, p. 71-91.

Matsuhisa, Y., Goldsmith, J. R., and Clayton, R. N., 1978, Mechanisms of Hydrothermal Crystallization of Quartz at 250-Degrees-C and 15 Kbar: Geochimica et Cosmochimica Acta, v. 42, p. 173-182.

Miller, M. F., 2002, Isotopic fractionation and the quantification of ${ }^{17} \mathrm{O}$ anomalies in the oxygen threeisotope system: an appraisal and geochemical significance: Geochimica et Cosmochimica Acta, v. 66 , p. 1881-1889. 
Mook, W. G., 2000, Environmental isotopes in the hydrological cycle principles and applications, V I: Introduction- Theory, Methods, Review, v. 1: Paris, UNESCO/IAEA.

Ono, S., Eigenbrode, J. L., Pavlov, A. A., Kharecha, P., Rumble, D., Kasting, J. F., and Freeman, K. H., 2003, New insights into Archean sulfur cycle from mass-independent sulfur isotope records from the Hamersley Basin, Australia: Earth and Planetary Science Letters, v. 213, p. 15-30.

Peck, H. D., 1959, The ATP-dependent reduction of sulfate with hydrogen in extracts of Desulfovibrio desulfuricans: Proceedings of the National Academy of Sciences of the United States of America, v. 45, p. 701-708.

1961, Evidence for reversibility of reaction catalyzed by Adenosine 5'-Phosphosulfate reductase: Biochimica et Biophysica Acta, v. 49, p. 621-624.

Rees, C. E., 1973, Steady-state model for sulfur isotope fractionation in bacterial reduction processes: Geochimica et Cosmochimica Acta, v. 37, p. 1141-1162.

Schauble, E. A., 2004, Applying stable isotope fractionation theory to new systems, in Johnson, C. M., Beard, B. L., and Albarede, F., editors, Geochemistry of Non-Traditional Stable Isotopes: Reviews in Mineralogy and Geochemistry, v. 55, p. 65-111.

Shen, Y. A., Buick, R., and Canfield, D. E., 2001, Isotopic evidence for microbial sulphate reduction in the early Archaean era: Nature, v. 410, p. 77-81.

Thamdrup, B., Finster, K., Hansen, J. W., and Bak, F., 1993, Bacterial disproportionation of elemental sulfur coupled to chemical-reduction of iron or manganese: Applied and Environmental Microbiology, v. 59, p. 101-108.

Thamdrup, B., Finster, K., Fossing, H., Hansen, J. W., and Jorgensen, B. B., 1994, Thiosulfate and sulfite distributions in porewater of marine-sediments related to manganese, iron, and sulfur geochemistry: Geochimica et Cosmochimica Acta, v. 58, p. 67-73.

Thamdrup, B., Canfield, D. E., Ferdelman, T. G., Glud, R. N., and Gundersen, J. K., 1996, A biogeochemical survey of the anoxic basin Golfo Dulce, Costa Rica: Revista De Biologia Tropical, v. 44, p. 19-33.

Thode, H. G., Monster, J., and Dunford, H. B., 1961, Sulphur isotope geochemistry: Geochimica et Cosmochimica Acta, v. 25, p. 159-174.

Troelsen, H., and Jørgensen, B. B., 1982, Seasonal dynamics of elemental sulfur in 2 coastal sediments: Estuarine Coastal and Shelf Science, v. 15, p. 255-266.

Urey, H. C., 1947, The thermodynamic properties of isotopic substances: Journal of the Chemical Society, p. 562-581.

Williams, J. S., 1967, Variance of weighted regression estimators: Journal of the American Statistical Association, v. 62, p. 1290-1301.

Young, E. D., and Galy, A., 2004, The isotope geochemistry and cosmochemistry of magnesium, in Johnson, C. M., Beard, B. L., and Albarede, F., editors, Geochemistry of Non-Traditional Stable Isotopes: Reviews in Mineralogy and Geochemistry, v. 55, p. 197-230.

Young, E. D., Galy, A., and Nagahara, H., 2002, Kinetic and equilibrium mass-dependent isotope fractionation laws in nature and their geochemical and cosmochemical significance: Geochimica et Cosmochimica Acta, v. 66, p. 1095-1104. 